\title{
Pre-service Technology Teachers' Experiences of Project Based Learning as Pedagogy for Education for Sustainable Development
}

\author{
Asheena Singh-Pillay \\ School of Education, Science and Technology Education cluster, University of Kwa Zulu Natal, South Africa
}

Received February 19, 2020; Revised March 23, 2020; Accepted March 28, 2020

Copyright $\bigcirc 2020$ by authors, all rights reserved. Authors agree that this article remains permanently open access under the terms of the Creative Commons Attribution License 4.0 International License

\begin{abstract}
This paper reports on a qualitative study, which embraced the interpretative paradigm. The study explored Pre-Service Technology Teachers' (PSTTs) experiences of Project-based learning (PBL) as pedagogy while learning about Education for Sustainable development (ESD) at a university in South Africa. The paper advances the rationale that adopting a pedagogy that contextualised PBL has allowed for transformation in the perception and behaviour of PSTTs about sustainability issues, critical citizenship as well as their role as future teachers. Furthermore, it improved the capacity of people to address environmental and developmental issues. Mezirow, theory on transformative learning guided the study theoretically. Fifty-four PSTTs, who were enrolled for the processing module in technology education in 2016, were purposively selected to participate in the study. Participants were assured of confidentiality and anonymity. Data was generated in three stages. This paper reports on stage two and three of data generation, which required PSTTs to participate in focus group interviews and maintain a reflective diary of their experiences of PBL and ESD. Data was subjected to thematic analysis. The findings revealed that $\mathrm{PBL}$ increased application of content to solve sustainability problems. Furthermore, the findings bring to the fore new dimensions to the learning that PSTTs experienced when they engaged in PBL, such as overcoming prejudices, team work, awareness of their social responsibilities to the community and the development of skills for sustainability change agents. These finding have implication for pedagogy used to infuse ESD within the curriculum and overcome social cultural stereotypes.
\end{abstract}

Keywords Education for Sustainable Development, Experiences, Pre-service Technology Teachers, Project Based Learning, Transformative Learning

\section{Introduction}

Education is construed globally as a conduit for arousing awareness of sustainability issues and to bring about a change in attitude, values and behaviour patterns of individual with regard to sustainability (Lieberman, 1977; World Bank, 2012). There is mounting pressure (globally) for teacher educators to embed Education for sustainable development (ESD) into the pre-service teacher-training curriculum (UNESCO, 2014) in order to facilitate the aforementioned transformation in terms of change in attitudes, behaviour and values among pre service teachers with regard to ESD and sustainability issues. International support for pre-service teacher programmes to teach ESD can be traced back to the 1971 European International Union for Conservation of Nature conference, the Belgrade Charter (UNESCO-UNEP, 1976) Tbilisi Declaration, Decade of education for sustainable development (UNESCO, 2004) and more recently UNESCOs Global Action Programme (GAP) which purports that sustainability begins with teachers (UNESCO, 2014). It is widely argued by Crawford (2016) that by including ESD in per-service teacher training programmes novice teachers will graduate with the capacity to embed ESD into their day-to-day work and, hence, enable widespread implementation in schools. The implication of UNESCOs GAP is that educational processes and systems can transform perspectives and behaviour patterns to bring about change in sustainable practice, civic responsibility and responsible citizenship (UNESCO, 2014). The GAP also emphasises that ESD requires learner-centred and interactive teaching strategies, for example, critical thinking, participatory decision-making, value-based 
learning, and multi-method approaches, all of which to some degree contrast traditional lecture-based teaching practices (Kalsoom,Khanam \& Quraishi, 2017 and García, Sureda-Negre \& Comas-Forgas, 2017). In light of the preceding point, it can be reasoned that the purpose of teaching ESD is to empower and motivate students to take action for sustainable development (Bentham, 2013). This means that the preceding envisaged change can only be achieve by altering practices, modify teaching methods and planning new assessments to hopefully change or improve pre-service teachers' attitudes towards ESD and sustainability issues. However, it is worth noting that in Higher Education Intuitions there is often no adequate institutional support and incentives for those academics willing to integrate ESD in their activities (Hoover \& Harder, 2014), and most of the efforts lie primarily on academics (Krizek Newport, White \& Townsend, 2012).

Within the South African context, support for the inclusion of ESD is embedded in the South African constitution, the bill of rights, the white paper on education and training and the national curriculum statements. According to the bill of rights (p, 6), "Everyone has the right to an environment that is not harmful to their health or well-being; and to have the environment protected, for the benefit of present and future generations". In-spite of global commitments and South African policies calling for ESD-oriented teaching approaches, it must be noted that within the South African context, policy in paper does not translate to policy in practice (Singh-Pillay \& Alant, 2015). Furthermore, there is very little empirical evidence on how these approaches are applied in classrooms at teacher training institutions or how effective these ESD oriented teaching approaches are at empowering and motivating Pre Service Teachers to take action for sustainable development. It is the aforementioned gap that this study intended to address.

This articles reports on a larger study that embraced an ESD oriented teaching approach in a technology education module within the Pre-service Technology Teacher (PSTTs) education curriculum at a particular teacher training institution in South Africa. The paper does not pay attention to the content learnt in the technology education module but reports on Pre-service Technology Teachers' (PSTTs) experiences of PBL while engaging in ESD.

The paper is structured in 6 section. The first section pays attention to the introduction, the second section focused on the study context. The third section discusses the conceptualisation of PBL and agency while the forth section is devoted to the methodology. The fifth section concentrates on the findings and discussion and is followed by the conclusion.

\subsection{Conceptualising the Study Context}

This research project is located within technology education (within the South African context technology education was only introduced in 1998 in the school curriculum and teacher training institutions). My decision to embrace an ESD approach in technology education is informed by the white paper on education, the national curriculum statement, the hand on, minds on and hearts on approach (HMH) (Pillay, 2004) and Mezirow's (1978) Transformative learning theory (TLT).

In the authors' hands on, minds on and hearts on (HMH) framework, hands on refers to learning via physical activities in a local context, such as building, planting, painting etc. The rationale is physical activities in a particular context allows one to be involved and invested in the process of learning. According to Pugh (2002), physical activities that require investment from the learner allow for reflection, transformation of perspective/s, result in changed behaviour and an increased engagement in sustainable community practices. Minds on refers to engaging the cognitive domain via contextualised project based learning (PBL). Contextualised learning connects learning to the learners' day-to-day experiences/ environment/ community therefore, it allows for "buy in, deep engagement, reflection in order to find personal meaning and relevance in the learning context (Dewey, 1910). The aforementioned connection gives continuity to the learning process as it allows learners to see the need to create new meaning from experiences by drawing connections and relations to previous experience, knowledge and ideas (Kolb, 1984). Reflection is the key to transformation of the learning experience (Mezirow, 1978). Hearts on refers to assisting or empowering the affective domain into forming values and attitudes that are translated into pro sustainability behaviours about the environment and sustainable development issues. Peoples' lives are sculpted by relationships and interactions with people and the environment (Riley-Taylor, 2002). These relations and interactions which impact a person's emotions, thoughts and behaviours serve as an impetus to reflect, change, to transform values and attitudes (Zembylas, 2003).

Transformative Learning Theory emphasises that transformation in learning occurs by changing learners' frame of reference (Mezirow, 1978). According to Mezirow (1978) frames of reference are fluid structures of assumptions through which we understand our experiences and the world around us. This means that frames of references are not fixed, they can be transformed on a daily basis through reflection of our interpretations, emotions, beliefs, habits or points of view. Changing ones frame of reference results in shifts in an individual's thoughts, feelings, and actions which results in a shift of consciousness and changes ones way of being in the world. Mezirow (1978) purports that to model transformative learning, teaching methods should allow learners to go through a process of critical reflection to ensure a transformation or change in their thinking and to make 
them realise the interconnectedness of self, the human community and the natural environment (O'Sullivan, 2008). Consequently, my teaching of technology education had to go beyond just teaching content-related knowledge and skills. It had to embrace new ways of thinking about $\mathrm{ESD}^{1}$, and the possibilities for change (especially within the South African context ${ }^{2}$ ). This meant, I had to ensure that the module outcomes, content delivery, teaching strategies and assessments used challenged PSTTs to reflect on their learning, change their attitudes and thought processes in order to inculcate sustainable living. Therefore, Project- based learning (PBL) was incorporated into my teaching. PBL is an inquiry based approach that provides opportunities to transform learning experiences by engaging learners in contextually relevant projects (Lee et al., 2014)

\subsection{Conceptualising Project-Based Learning and Agency in ESD}

Project based learning is a teaching approach that engages learners in learning essential knowledge and life-enhancing skills structured around complex, authentic questions and carefully designed projects (Awases, 2015). PBL embraces a constructivist approach to teaching and learning of ESD (Illeris, 2007). The constructivist approach to learning advocates that learners are actively engaged in the learning process, they mobilise knowledge, integrate new knowledge and produce new meanings (Patil $\&$ Kudte, 2017) as opposed to teacher centred approaches. Contextualised PBL requires the use of real situations as point of departure for learning, in which learners mobilise knowledge and construct new knowledge to solve problems (Hartman, Renguette, \& Seig, 2018; Kolmos, de Graaff, \& Du, 2009). In traditional learning environments, attention to the context in which learning takes place as well as the interaction between learners and the surrounding environment is neglected (Illeris, 2007). In $\mathrm{PBL}$, real contexts are brought into education, and the contexts are to be meaningful and concrete to the learner. For their PBL PSTTs were expected to identify a 'problem' relating to poor use of resources / waste reduction / management and recycling in the community and with the community jointly address and resolve this identified problem $^{3}$. In these contexts, learners develop a deeper and strategic approach to learning which is characterised by intentions to understand; interactions with content; relations between new ideas and prior knowledge; relations

1 The following sustainable development goals were espoused via my teaching, quality education, gender equity, wise use of non-renewable resources, no pollution, responsible consumption, reduce greenhouse gases and conserve aquatic environments.

2 Many South African still carry historical prejudices relate to apartheid with them

3 Problems identified and addressed via PBL included: burning of wasteincreasing the carbon footprint; illegal dumping of waste leading to infestation of pests/rodents; pollution of stream leading to poor quality drinking water; non-recycling of plastics; excessive harvesting of trees for fire wood; poor construction of informal dwellings. between concepts and everyday experiences; time management, etc. These are example of complex cognitive tasks that move beyond memorising and reproducing knowledge (Savin-Baden \& Howell, 2004). The active role of the learners and the role of the environment as the place to act are stressed in PBL. PBL allows learners to develop analysis, learning and solving strategies capable to be transferred to other contexts (Silva, Bispo, Rodriguez, \& Vasquez, 2018; Dolmans, Grave, Wolfhagen, \& Van der Vleuten, 2005). This means that in PBL the teacher's role changes from a distributor of knowledge to a process manager, helping learners in their learning process by initiating reflection processes and supporting them, if necessary, on substantive matters In other words, the action and learning are inextricably linked and can be critiqued leading to revision and further learning. Contextualised PBL allows for emergence of human agency through the learning process based on interactions between humans and the context.

I embrace an ecological perspective on agency, which sees agency as an emergent phenomenon of the context through which it is enacted (Singh-Pillay \& Samuel, 2017). This means that agency is not an inherent quality that individuals possess, it is something people do in response to a particular context to overcome contextual challenges/ issues or problem. Agency (or the lack thereof) will therefore always result from the interplay of individual efforts, available resources, contextual and structural factors as they coalesce in particular and unique situations (Tan, 2016). Agency is an embedded process of engagement influenced by the past, orientated towards the future and engaged with the present. The above notion of agency illuminates that agency does not come from nowhere, but builds upon past achievements, understandings and patterns of action. Agency is therefore a dialogical process via which actors immersed in context engage with each other or issues.

\section{Methodology}

\subsection{Design}

This qualitative study adopted a case study design. Creswell and Creswell (2017) defined a case study as "an in-depth exploration of a bound system which could be an activity, event, process or individuals" (p. 462). In this study, the case explored is PSTTs' learning experiences of PBL while engaging in ESD.

\subsection{Ethics}

Written consent to embark on this research project was obtained from the relevant gatekeeper at Edgemond University (Pseudonym). Participants were informed of the research protocol, assured of confidentiality, 
anonymity and that participation was voluntary.

\subsection{Sampling}

Participants were purposively selected, the criteria being that they had to be enrolled for the processing module in technology education. In purposive sampling, participants are selected on the basis that they are most likely to generate useful information (Kumar, 2011). The sample consisted of 54 PSTTs enrolled for the processing module in 2016. PSTTs self-selected their groups for the contextualised community PBL. Six group ${ }^{4}$ with 9 PSTTs were formed.

\subsection{Data Generation}

In the first stage of data generation PSTTs engaged in PBL within their communities to identify problems related to sustainability. During the second stage of data generation PSTTs worked with the communities to come up with solutions to the problems identified related to sustainability. Photo journals were maintained by each group for stages one (to document the problems identified in the community). Focus group interviews were also conducted for stage two of data generation and in the third stage of data generation each PSTTs maintained a reflective diary to record their individual perceived learning experiences of PBL while engaging in ESD. The focus group interviews were audio recorded and transcribed verbatim. Six focus group interviews were conducted. The interview was of 30 minute duration. For the purpose of this paper, data from the focus group interview and reflective diary was used.

\subsection{Data Analysis}

All the reflective diaries (54) were subjected to thematic analysis. The purpose was to derive information about PSTTs' experiences of PBL while engaging in ESD. Diaries were numbered from 1-54. Journal entries were read, and re-read before patterns could be identified (Braun \& Clarke, 2006) and coding could begin. Journal entries and focus group interview transcript were sent to the respective PSTTs for member checking. Member checking also known as participant or respondent validation, it is a technique for exploring the credibility of data. Initial codes assigned were re-examined and re-grouped in order to refine emergent themes. The emergent themes were also returned to PSTTs to check for

\footnotetext{
4 Each group negotiated and decided what role each member should play based on their strengths. the following roles were identified: spokesperson for the group to liaise with the community and handle all communication issues, team leader- to tack time frames check contribution of group, teams researchers- all 9 had to research/brainstorm /design solution to problem identified, task performers (all 9 as per negotiations), reporting all 9. The lecturer served as a facilitator asking relevant questions to redirect PSTTs to the content needed to address the issues identified.
}

accuracy and resonance with their experiences.

\section{Results and Discussion}

This section reports on the thematic analysis of data from the reflective dairy and focus group interviews to respond to the research question: What are PSTTs' learning experiences of PBL when they engage in ESD.

Thematic analysis indicates that PSTTs have 3 key learning experiences about PBL while engaging in ESD, namely

- $\quad$ PBL promotes social learning

- $\quad$ PBL promotes real world context for learning about ESD

- $\quad$ PBL as a catalyst for pre-service teachers' awareness of their role as agents of change

In the reporting of the findings and discussion, codes for the participants are represented as P1, P2 and so on.

\subsection{PBL Promotes Social Learning}

Project based learning provided PSTTs with reflective spaces to question, (re)examine their (un)conscious values, beliefs and judgements in life as is visible in the excerpts below:

"I don't like working in groups but in this project, I had a chance to get to know people in my group, I normally don't speak to them, we are faces in the same lecture room. They treated me kindly, were so warm towards me. I think I was bias towards people of colour. I enjoyed this project and realised we are all the same, have same fears, hopes and dreams, there's no difference. The best part was I learnt how to be a team player, not to be judgemental, to be confident; this was a humbling experience for me. I gained more skills during this project than passing any exam" (Reflective diary P37)

"My fear of foreign students is waning, I'm not so suspicious of them anymore, I'm learning to get along with the Yiadom. He told me about his families experiences in the township during the xenophobic attacks" (Reflective diary P15)

Similar views were expressed during the focus group interviews.

I realized problem solving becomes easier and solutions are reached faster when we work together. I am independent I work by myself, in this project I learnt about group dynamics, trust, to listen to other voice, to share ideas, I learnt about team work, strengths and weakness and how to help and be helped. I'm learning isiZulu. I am aware of my social responsibility towards my community. It is rewarding to help other" (Focus group interview, P12) 
The excerpts above confirm that PBL allows for collaborative reciprocal learning, promotes deep thinking about actions, helps to break stereotypes and allows PSTTs to belief in the good of others. The reflective space that PBL provided helped PSTTs to gain a better understanding of themselves (I realized) and others (we are not different) as they explored and developed ways to contribute to the community, they were working in. It allowed for introspections of the self and their working relations with people of different ethnicities and socioeconomic statuses, leading to PSTTs developing self-confidence (to be confident), team building (enjoyed this experience.) reduced anxieties, increased tolerance related to perceived differences between race, cultures and backgrounds (normally don't speak to them) and enhanced commitment to group work.

In other words, PSTTs' engagement in PBL helped them to break down stereotypes shaped by the particular historical legacies in South Africa. Furthermore engaging in PBL produced positive feelings toward group members and developed collegial relationships, this particular finding resonates with that of Singaram, van der Vleuten, Stevens and Dolmans, (2011)'s study conducted among South African medical school students. These scholars reported that medical school students initially displayed biasness towards their PBL team members from different ethnic and racial backgrounds, the biasness was attributed to their segregated schooling and upbringing and that by engaging in PBL the students learnt to overcome the biasness and prejudices they held. The above excerpts highlight the emotional catharsis that PSTTs experienced during PBL. Further, it is evident that the reflection processes attached to PBL were liberating as they provided PSTTs with the skills needed to successfully manage life tasks such as identifying anxieties, labelling emotions, learning in groups, teamwork, awareness of themselves and others, the need for kindness and respect for others, forming relationships, care about others, make good decisions, behave ethically, avoid negative behaviour and overcoming biases. Being able to manage life tasks and emotions is what Zins, Weissberg, Wang and Walberg (2004) refer to as emotional learning. This means that PBL provided a platform for emotional learning. Sen (2009) asserts that emotional learning is an integral part of what concerns education, as it bring to the fore the humanistic dimension of teaching and learning. In a subdued way the emotional competencies pre-service teachers need to be able to relate to each other and their learners in the South African context is brought to the fore. These are all critical skills for the future success of education and of our response to sustainability goals (Bell, 2010). The above findings show the powerful and transformative nature of PBL, in terms of shifting existing frames of references. The change in PSTTs frame of reference has resulted in shifts in an individual's thoughts, feelings, and actions.

\subsection{PBL Promotes Real World Context for Learning about ESD}

The majority of PSTTs (51 out of 54) expressed that PBL provides the ideal opportunity to learn about ESD as is visible in the excerpts below:

This is real learning, you can seek the link between the theories, practical, it brings the chemistry of plastics to life. We need more of PBL, it is better than any textbook or classroom lesson, you get the chance to apply theory not just to pass the exam but to solve contextual problems in the community, and the community benefits you can see the impact of plastic on the environment, the challenges the community faces, burning of plastic, burning of shacks, deaths from illegal electricity connections the lack of clean drink water, landfills and how it affect the lives of those who live close by, its hand on. I would not have considered the impact of illegal dumping and landfills if we didn't engage in this PBL activity. Dr. P goes on and on about voice and agency- I get it now, you get to connect with the community, reflect and think critically. We can make a difference and use our context as the biggest teaching resource, you really don't need state of the art infrastructure to promote ESD, I was involved in the learning, identifying the problem, working with the community to find the solution and I liked it, I got to solve real life problems on disposal of plastics, I worked with them and I got a better understanding of the problem and sustainability issues, I thought the community how to waterproof their dwelling, how to use paraffin safely about composting and the need to recycle (Reflective diary, $\mathrm{P} 31$ ).

Identical views were expressed during the focus group interviews.

You can't learn about ESD in a classroom and not use the information to transform communities. PBL was an eye opener for me. I come from an advantaged background, I could only imagine what a child headed household or living in a shack was but now I have seen it and the constant struggle poor communities experience daily. As future teachers we need more PBL type of projects to see the link between what we learn and how this learning can be used to transform the communities in which we work/live I'm sold on this kind of engagement." (Focus group interview, P41).

The above excerpts reveal that PBL ensured continuity of the learning experience (link theory to the real world) by promoting opportunities to practice and apply content and skills learnt in lectures (It's hands on) to solve real contextual problems. The above findings concur with that of Papert (1991) and Larmer and Mergendoller, (2010), who assert that in PBL knowledge is not simply transmitted from teacher to student, but actively constructed in the mind of the learner, when they actively engage in coming 
up with unique solutions to the problems identified. From the excerpts above it is visible that PBL also allowed PSTTs to engage with and interact with the community context and for action to be undertaken rather than passively receiving information (You can't learn about ESD in a classroom). By engaging in PBL, PSTTs become conscious of historical South African social realities (child headed household, constant struggle) and day to day contextual challenges in terms of ESD that many communities continue to encounter lack of clean drinking water, burning of shacks, deaths from illegal electricity connections). The aforementioned awareness is important in teaching especially when learners in schools come from diverse backgrounds, as it will equip PSTTs to be mindful of the learners' contextual background and to help mitigate biasness towards learner/communities. It is thus reasoned that PBL contributed to the development of social capital for both PSTTs and the community. PBL served as a vehicle to validate students' experiences and bridge the cultural division between the PSTTs, university and the community. PBL offered PSTTs a chance to experience ESD as a practice-based approach. It allowed PSTTs to take ownership of their learning as active participants thereby allowing them to gain information, skills and attitudes to encourage sustainable practices in their communities. In this way, PBL not only developed PSTTs' critical thinking, research and problem-solving skills, but also gave them experience in applying these skills to real world situations as noted in Genc, 2015 study, which reiterates that PBL offered pre-service teachers a chance to experience the tangible reality of the problems in their communities, as well as take ownership of the project as active participants rather than mere consumers of knowledge. Through their participation in PBL, pre-service teachers seemed to be able to gain information, skills and attitudes for a sustainable environment in their community; through learning-by-doing and solving problems surrounding sustainability in their context areas, and understanding that ESD is practice-based. This way, PBL not only developed pre-service teachers' critical thinking, research and problem-solving skills, it gave them experience in applying these skills to real world situations (Nation, 2008).

In this study PBL also led to the empowering of the communities (the PSTTs worked in) concerning ESD issues (recycling, waterproofing dwelling, using paraffin) that impacted them daily and assisted them having 'safer' dwellings and using materials safely. The above excerpts also reveal the kind of learning PSTTs appreciate, namely, active learning strategies that promote community engagement and reflexive thinking.

\subsection{Project Based Learning as a Catalyst for Pre-service Teachers' Awareness of Their Role as Agents of Change}

By engaging in PBL, PSTTs had multiple opportunities for deeper inner reflection. My data reveal two contradictory finding in terms of PBL as a catalyst for PSTTs' awareness of their role as agents of change. On the one hand reflections allowed 51 PSTTs to (re)evaluate their frame of reference with regard to what a teacher's job is and what it is not as is visible in the excerpts below:

"If it wasn't for this project, I would have ignored the impact of people's actions on the environment and sustainable use of resources. To me this was something you learn about, teach it and forget about it. Bringing change is not my job, my job will be just to teach, now I feel differently, I have changed, it's not just about learners in school it's also about my learning as a lifelong learner, I have changed because of this project, my thinking about me as a teacher and my role in the community has changed, I can use my teacher voice to change people's lives, improve our society, it's my responsibility, I now care about my community" (Reflective diary, P 25)

\begin{abstract}
"I know now that change can be little steps we take to improve the quality of life for others in our community, it doesn't have to be grand and fancy. Working on this project allowed me to see that I can contribute to change. Even though this project was on plastics and ESD, I found I could not ignore the lack of clean drinking water, asthma, and took it upon myself to tell the mother the importance of sterilizing the water before drinking. I even demonstrated how to do this using bleach. I felt inspired and would want to do this type of project again. I will engage my learners in this type of project when I start teaching, this is real contextualized learning, you don't need fancy resources for this" (Focus group interview, P46)
\end{abstract}

The above excerpts highlight the transformative learning that occurs by engaging PSTTs in PBL while trying to create sustainable communities. By using, the community as a resource PSTTs had an opportunity to (re)align their frames of references. The consequence of the realignment of their frame of reference was a transition from ignorance of the social responsibilities attached to teaching (it not my $j o b)$ to a greater sense of awareness of the need to bring about change, transformation and social justice in the communities they are working in (this is my responsibility; I can make a difference). PBL allowed PSTTs to be conscious of their roles as agents of change in the communities they worked in; they became aware of power or social capital (teacher voice), inequalities that prevail and their civic responsibility towards the community. PSTTs are able to see how their role as agent of change extends from the classroom /school to the community. These PSTTs were able to see the power linked to the professional identity of a teacher and the capacity to produce change and be drivers of ESD (UNESCO, 2014). These participants see teaching as a moral ethical value 
laden practice. Powers (2004), in her evaluation of school community place-based projects in the United States, found that this approach increases students' interest in their community issues. These findings confirm that the approach that I am using in my teaching makes a difference to how PSTTs think about ESD and their role as agents of change. PBL lead to caring eco-literate PSTTs who reflected upon their (communities) impact on their environment (Orr, 1992; Theobald, 2000).

On the other hand three of the 54 PSTTs did not enjoy engaging in PBL nor do they see themselves as agents of change. These PSTTs have a rigid view of what learning entails or where it should occur as well as the role of teachers and schools. They are unable to experience or see learning as a transformative process that links their thoughts, actions, emotions, beliefs to new forms of realities (Jarvis, 2006). Their values are not rooted in social justice as can be gathered from the excerpts below:

"This is not for me- this ESD, who cares about the environment- I don't, this ESD it's not technology related, other tech modules don't have it, I see it as a waste time"(Reflective diary, P22)

"There is too many assessments, we do practical's, have a task to complete after each lecture, have assignments and then have a project based with a community- ahaai these communities its so dirty why must we go outside the lab or Edgemond. I'm so clean for this kind of work, I broke my nail outside, my weave got damaged, I'm not interested in the community or how they use resources/dispose plastics. This is not a teacher's job, teachers get paid to teach not to do work in the community or worry about community issues. None of the township teachers, where I come from, do this with their learners so I can't start this, I will just teach in the classroom and get paid" (Focus group interview, P2)

"I don't see myself as this agent of change- I can't change the world, that not what teaching is about- my job is to get learner to pass, hey this lecturer is demanding to much" (Focus group interview, P26)

The excerpts above reveal the rigid concept that these 3 PSTTs have of their selves, of who they are, what teaching entails and how they see themselves performing their teaching duty. Their views impact the nature of their agency (or lack of agency). Their rigid view on teaching, (job is to get learner to pass; teachers get paid to teach not to do work in the community or worry about community issues) and learning (to pass) as well as their own teaching and learning experiences (None of the township teachers, where I come from, do this with their learners) deprive them from reflecting on contextual issues encountered during PBL. Hence they are (un)able to (re)align their existing frames of references. These 3 PSTTs have a very narrow myopic view on the role of teaching which is aligned to Naylor and Sayed's (2014) study which raises that the pertinent question is teaching about getting learners to pass exams. These three PSTTs do not see the role of teachers as being linked to and taking responsibility for social programs that concern communities as alluded to by Roux and Becker, (2016). The above finding brings to the fore the limits of my agency to effect change among a few PSTTs to embrace all the roles that are asked from teachers. Within the SA context, many experiences remain influenced by historical legacies and continue to manifest themselves in various ways impacting how we perceive and experience our roles as teachers. These PSTTs narrow view on what teaching entails will influence how they engage learners during teaching (in the future), their tolerance, respect, care and how they model interpersonal relationships among learners.

\section{Conclusions}

The findings of this study bring to the fore the reflective spaces provided by PBL, which allowed PSTTs to question, (re)examine their (un)conscious values, beliefs and judgements. Three key findings emerged. The first finding relates to the "social learning" that occurred during PBL, such as overcoming stereotypes, developing positive collegial relationships, labelling emotions, forging team spirit, recognising kindness, exercising care, behaving ethically, avoiding negative behaviour and overcoming biases (Zins et al., 2004). This type of "social learning" is invaluable in teaching (it often absent in a formal classroom lesson) as it highlights the emotional competencies teachers draw upon when they have to relate to learners. The second finding illuminates that PBL provided a real world context for learning about ESD. PSTTs had the opportunity to link and apply content and skills gained in the lectures to solve contextual problems in their communities such as recycling, pollution, waterproofing of dwellings, and wise consumerism of resources. It also made PSTTs aware of contextual social realities communities experience and about the quality and state of the environment. Engaging PSTTs in PBL did not only increase their understanding and application of the content but also instill in some of them the importance of action and engagement throughout their lives, both of which are vital skills for sustainability and change agents (Segalas, et al. 2010). The third finding talks to the arousal of teacher agency during PBL. The finding exemplifies that trying to promote change agency isn't simply about taking action during PBL but also about understanding the implications of our actions, which requires emotional intelligence, interpersonal skills, and understanding of historical legacies and potential solutions. The findings from this study confirm that promoting ESD agency amongst PSTTs is a complex and requires new 
ways of educating for behaviour change.

In terms of pedagogy, the findings of this study show that combining the HMH approach, TLT and PBL with an ESD lens in the teaching is successful as these models collectively require a change in perception, a change in values and active engagement. The model reflects that transformation is a multi-dimensional process and that changing sustainability values and environmental paradigms require more than a logical argument or an emotional appeal.

\section{REFERENCES}

[1] Awases, C. (2015). Secondary school Geography teachers' understanding and implementation of learner-centred education and enquiry-based teaching in Namibia. Unpublished master's thesis. University of Stellenbosch.

[2] Bell, S. (2010). Project-based learning for the 21st century: Skills for the future. The Clearing House: A Journal of Educational Strategies, Issues and Ideas, 83(2), 39-43.

[3] Bentham, H. (2013). Clearing the Path that Has Been Laid: A Conceptualisation of Education for Sustainable Development. Journal of Teacher Education for Sustainability, 15(2), 25-41.

[4] Braun, V. \& Clarke, V. (2006). Using thematic analysis in psychology. Qualitative Research in Psychology, 3, 77-101.

[5] Constitution of the Republic of South Africa, 10 December 1996, available at: http://www.refworld.org/docid/3ae6b5d e4.html [accessed 20 March 2016]

[6] Creswell, J. W., \& Creswell, J.D. (2017). Research design: Qualitative, quantitative, and mixed methods approaches. London: Sage Publications.

[7] Dewey, J. (1910). How We Think. Lexington, MA D.C. Heath and Company.

[8] Dolmans, D. H. J. M., De Grave, W., Wolfhagen, I. H. A. P., \& van der Vleuten, C. P. M. (2005). Problem-based learning: Future challenges for educational practice and research. Medical Education, 39(7), 732-741. doi:10.1111/j.1365-2929.2005.02205.

[9] Genc, M. (2015). The project-based learning approach in environmental education. International Research in Geographical and Environmental Education, 24(2), 105117.

[10] Hartman, P., Renguette, C., \& Seig, M. (2018). Problem-Based Teacher-Mentor Education: Fostering Literacy Acquisition in Multicultural Classrooms. Interdisciplinary Journal of Problem-Based Learning, 12(1). Available at: https://doi.org/10.7771/1541-5015.1659.

[11] Hoover, E., Harder, M.K., 2014. What lies beneath the surface? The hidden complexities of organizational change for sustainability in higher education. J. Clean. Prod. 106, 175e188. https://doi.org/10.1016/j.jclepro.2014.01.081.
[12] Illeris, K. (2007). How We Learn: Learning and Non-learning in School and Beyond. London/ New York: Routledge.

[13] Jarvis, P. (2006). Towards a Comprehensive Theory of Human Learning. Abingdon: Routledge.

[14] Kalsoom,Q, Khanam,A., \& Quraishi,U. (2017) Sustainability consciousness of pre-service teachers in Pakistan", International Journal of Sustainability in Higher Education, 18(7),. 1090-1107, https://doi.org/10.1108/IJSHE-11-2016-0218

[15] Krizek, K.J., Newport, D., White, J., Townsend, A.R., 2012. Higher education's sustainability imperative: how to practically respond? Int. J. Sustain. High Educ. 13 (1), 19e33. https://doi.org/10.1108/14676371211190281

[16] Kolb, D. A. (1984). Experiential Learning Experience as the Source of Learning and Development. Englewood Cliffs, NJ Prentice Hall.

[17] Kolmos, A., de Graaff, E., \& Du, X. (2009). Diversity of PBL-PBL learning principles and models. In X. Du, E. de Graaff \& A. Kolmos (Eds.), Research on PBL practice in engineering education (pp. 9-21). Rotterdam: Sense Publishers.

[18] Kumar, R. (2011). Research Methodology A Step-by-Step Guide for Beginners. 3rd Edition. Sage, New Delhi.

[19] Lee, J. S., Blackwell, S., Drake, J., \& Moran, K. A. (2014). Taking a Leap of Faith: Redefining Teaching and Learning in Higher Education Through Project-Based Learning. Interdisciplinary Journal of Problem-Based Learning, 8(2). Available at: https://doi.org/10.7771/1541-5015.1426.

[20] Lieberman, C. (1977). "Education and social change," American Secondary Education, vol. 7(3), 42-48.

[21] Mezirow, J (1978). Perspective Transformation. Adult Education, 28, 100-110.

[22] Nation, M. L. (2008). Project-based learning for sustainable development. Journal of Geography, 107(3), 102-111.

[23] Naylor, R. \& Sayed, Y. (2014). Teacher quality: Evidence review. Office of Development Effectiveness: Commonwealth of Australia.

[24] Orr, D. (1992). Ecological literacy: Education for a post modern world. Albany, NY: State University of New York.

[25] O'Sullivan, E. (2008). Finding our way in the great work. Journal of Transformative Education, 6, 27-32.

[26] Patil, A., \& Kudte, S. (2017). Teaching learning with constructvist approach. International Journal of Engineering Development and Research, 5(4), 308-312.

[27] Pillay, A (2004). An exploration of biology teachers' practice with regard to practical work and how it relates to the NCS-FET life science policy document. Unpublished masters thesis. University of Kwa-Zulu Natal.

[28] Powers, A. L. (2004). An evaluation of four place-based education programs. The Journal of Environmental Education, 35(4), 17-32.

[29] Pugh, K. J. (2002). Teaching for Transformative 
Experiences in Science: an Investigation of the Effectiveness of Two Instructional Elements. Teachers College Record, 104, 1101-1137.

[30] Riley-Taylor, E. (2002). Ecology, spirituality, and education: Curriculum for relational knowing. New York, NY: Peter Lang Publishing, Inc.

[31] Roux, C., \& Becker, A. (2016). Humanising higher education in South Africa through dialogue as praxis. Educational Research for Social Change, 5(1), 131-143.

[32] Savin-Baden, M \& Howell, M.C. (2004). Foundations of problem based learning. Open university press. England.

[33] Segalas, J. Ferrer-Balas, D., \& Mulder, K.F. (2010). What do engineering students learn in sustainability courses? The effect of the pedagogical approach. Journal of Cleaner Production, 18, 275-284.

[34] Sen, A. (2009). The idea of justice. London: Penguin.

[35] Silva, A., Bispo, A., Rodriguez, D. and Vasquez, F. (2018). Problem-based learning: A proposal for structuring PBL and its implications for learning among students in an undergraduate management degree program, Revista de Gestão $\square, 25$ (2), 160-177. https://doi.org/10.1108 /REGE-03-2018-030

[36] Singaram, V. S., van der Vleuten, C. P., Stevens, F., \& Dolmans, D. H. (2011). For most of us Africans, we don't just speak: a qualitative investigation into collaborative heterogeneous PBL group learning. Advances in health sciences education: theory and practice, 16(3), 297-310. https://doi.org/10.1007/s10459-010-9262-3

[37] Singh-Pillay, A \& Alant, B. (2015) Tracing the Policy Mediation Process in the Implementation of a Change in the Life Sciences Curriculum, African Journal of Research in Mathematics, Science and Technology Education, 19(1), 12-2. , DOI: 10.1080/10288457.2014.100229

[38] Singh-Pillay, A., \& Samuel, M. A. (2017). Life Sciences Teachers Negotiating Professional Development Agency in Changing Curriculum Times. EURASIA Journal of Mathematics, Science and Technology Education, 13(6), 1749-1763.

[39] Tan, C. (2016). Teacher agency and school based curriculum in China's non-elite schools. Journal of educational change, 17(3), 287-302.

[40] Theobald, P. (2000). Communities as curricula. Forum for Applied Research and Public Policy. 15, 106-11.

[41] UNESCO. (2014). Shaping the Future We Want. UN Decade of Education for Sustainable Development (2005-2014)

[42] UNESCO. (2004). EFA Global Monitoring Report for 2005. Education for all: The Quality Imperative. Paris: UNESCO. Final Report. Paris, France.

[43] Winter, C., \& Firth, R. (2007). Knowledge about Education for Sustainable Development: Four Case Studies of Student Teachers in English Secondary Schools, Journal of Education for Teaching, 33(3), 341- 358.

[44] World Bank. (2012). Can low cost-private schools improve learning? Washington DC: Human Development Network, The Wold Bank.
[45] Zembylas, M. (2003). Emotions and teacher identity: A poststructural perspective. Teachers and Teaching: Theory and Practice, 9(3), 213-238.

[46] Zins, J., Weissberg, R., Wang, M., \& Walberg, H. (2004). Building academic success on social and emotional learning: What does the research say? : Teachers College Pr. 